\title{
Enablers and Disablers for Operational Integration in a Craft Oriented- versus a Mass Production Enterprise
}

\author{
Inger Gamme* and Catrine Eleonor Larsson \\ Gjøvik University College/Norwegian Science of Technology, Gjøvik/Trondheim, Norway \\ \{inger.gamme, catrine.larsson\}@hig.no
}

\begin{abstract}
Companies today are struggling to cope with ever changing requirements arising from environmental concerns and increasing competition. Hence it is important to innovate, improve, and increase efficiency by achieving streamlined value chains. In this paper we examine both a single craft-oriented leisure boat producer and a car component mass producer to find similarities and differences with regard to operational integration in these two types of organizations. The study is based on interviews and field studies carried out at the production line. From this study several common enablers for integration are found: informal culture and little hierarchy, little distance between process steps and mutual rewards. The differences were found in degree of standardization and formalization, connecting links between departments and knowledge of overall and departmental strategy.
\end{abstract}

Keywords: Craft, mass production, operational integration, information sharing, collaboration.

\section{Introduction}

The increasing challenges that production companies are facing nowadays must be met by corresponding improvement in the efficiency of the supply chain. To be able to cope with the complexity that continuous changes cause, it is important not only to focus on improving each process step, but also to ensure that there is integration between the process steps. Under these conditions, optimization of collaboration and information sharing could provide a competitive advantage [1]. In existing research there are few empirical studies focusing on antecedents to integration [2].This article focuses on the similarities and differences in operational integration between internal process steps in the production line of a craft-oriented manufacturer versus an industrialized mass producer (hereafter referred to as "CP" and "MP", respectively). Therefore, the overall aims of this article are as follows:

- What are enablers and disablers for operational integration?

- Is there a difference between these two sectors?

\footnotetext{
* Corresponding author.

B. Grabot et al. (Eds.): APMS 2014, Part I, IFIP AICT 438, pp. 217-224, 2014.

(C) IFIP International Federation for Information Processing 2014
} 


\section{Theory}

\subsection{Craft Oriented vs Mass Production}

Five different production paradigms are in use in modern times: Craft Production, Mass Production, Flexible Production, Mass Customization and a paradigm that has become relevant in recent years, sustainable production [3]. In this article we focus on Craft and Mass production.

Craft oriented enterprises are typically organized in a more informal way than larger companies and are characterized by the use of tacit knowledge and, typically, a flat organizational structure with few resources [4]. They often have a fire-fighting mentality with an emphasis on ad hoc decision making [5], and tend to have different needs and decision making process than larger firms [6]. Operational processes seem to be more acknowledged than managerial processes. Craft production can be defined as: "Skilled workers, using general purpose machines, making exactly the product that the customer paid for, one product at a time "[7].

Mass production can be defined as manufacturing a very large amount of identical products, and selling them to customers that the company is sure will be there to buy them. An increase in production volume requires more standardization of the processes. At the same time, an increase in production volume also makes it possible to reduce prices, thereby making it possible for more customers to buy the products [3].

\subsection{Operational Integration}

Many authors have focused on the interdependencies between two different process steps, but the content and framing varies, and many authors refer to the topic of operational integration without presenting a specific definition[8]. The term "coordination" has been used to describe managing dependencies between activities, meaning arranging the work tasks of two or more groups so that the groups can work together efficiently and hence achieve a common understanding of the work done by each of the groups [9]. The common goals for the groups are aligned, but the groups are separately responsible for performing their own work tasks [10].

In the literature there has been considerable emphasis on the "why" of integration, but comparatively little focus on how to achieve good integration [2, 8]. Promoting a positive attitude towards other departments is one way in which line managers can enhance integration [2]. In addition, when departments are equally responsible for achieving their aligned company goals, this circumstance tends to improve operational integration. Degree of operational integration can depend on elements such as reward systems, amount of formal and informal communication, organizational structures, and even different company cultures might $[8,11]$. Job rotation is also shown to be effective, and has been found to be mildly connected to integration in small companies, and strongly connected to integration in make-to-order companies [2]. Different companies may have different needs with respect to integration [12]. Aiming towards full integration is not always the answer, and as argued by Katz and Kahn [13], integration can be pushed too far. 


\section{$3 \quad$ Method and Material}

The data presented in this article represent two different research initiatives. The two companies were chosen because they represent two different production paradigms, and the aim of this study was to examine the question of whether operational integration varies according to the type of organization.

The first case study was funded by the Norwegian Research Council, and was undertaken with the primary objective of developing effective, competitive and profitable production within a leisure boat and craft-oriented industry in Norway. The goal of preserving the craft tradition while moving towards industrialization was emphasized. The case company used primarily manual manufacturing processes.

The second case study was an independent research initiative by two PhD Candidates whose projects were funded by the Norwegian Research Council. The aim was to study mechanisms for operational integration in the production line. The company chosen was a car component producer for commercial vehicles, one that produced a high volume of products. This company was also located in Norway, but was part of a larger group with operations on four continents.

A case study is one of various ways of doing science. It is a useful approach to understand complex social occurrences and to achieve understanding of organizations [14]. Table 1 lists the essential characteristics of the two case companies.

Table 1. Case Company Characteristics

\begin{tabular}{lll}
\hline Characteristics & Craft Producer & Mass Producer \\
\hline Years of study & 2008-2012 & $2012-2013$ \\
Main product & Leisure boats & Commercial vehicle components \\
Number of employees & 20 & 37 \\
Formal interviews & 12 & 11 \\
Part of value chain & Molding, pre-assembly, & Injection molding, assembly \\
included & assembly & \\
Type of informants & Operators, foremen, manager, & Operators, production manager, \\
& production manager. & foremen, planner, tool manager, \\
& & quality technician \\
\hline
\end{tabular}

This research is based on two single case studies. The use of fewer cases facilitates more in-depth analysis, but affords less opportunity to draw generalized conclusions. To increase the robustness of the research[15], data triangulation was used. It can be achieved by the use and combination of different methods such as surveys, interviews, observations and content analysis of documents to study the same phenomenon[16]. Prior to both studies a research protocol with an interview guide was worked out. Several semi-structured interviews were conducted to identify the operational integration for the production lines and its enablers and disablers. Semistructured interviews are defined as planned interactions for which some predefined guidelines are outlined, so the informant can provide important insight into facts in addition to their opinions on a desired topic [16]. The informants were given the possibility to answer freely and to offer additional information. In addition to the interviews, content analysis of documents, formal and informal meetings and direct 
observations were performed. Most of the time at both companies was spent on the shop floor interacting with the workers. Typically the focus of these meetings was on clarifying questions and discussing findings and special issues.

The collected data were recorded on a dictation machine, analyzed and coded into main categories $[16,17]$ to identify the mechanisms for operational integration.

\section{$4 \quad$ Findings and Discussion}

To organize the data, categories are developed on the basis of previous work by different researchers who have found the overall mechanisms for integration to be culture at the plant, degree of vertical integration and formalization, facility and layout, degree of use of information systems, consensus on integration and measurements and rewards $[2,8,12,18]$. The mechanisms from the different researchers are combined and further developed to form the basis for the organization of our data. These categories and findings are shown in Table 2. It should be mentioned that some of the enablers and disablers could fit into more than one group.'

Table 2. Enablers and disablers for integration in the MP and the $\mathrm{CP}$

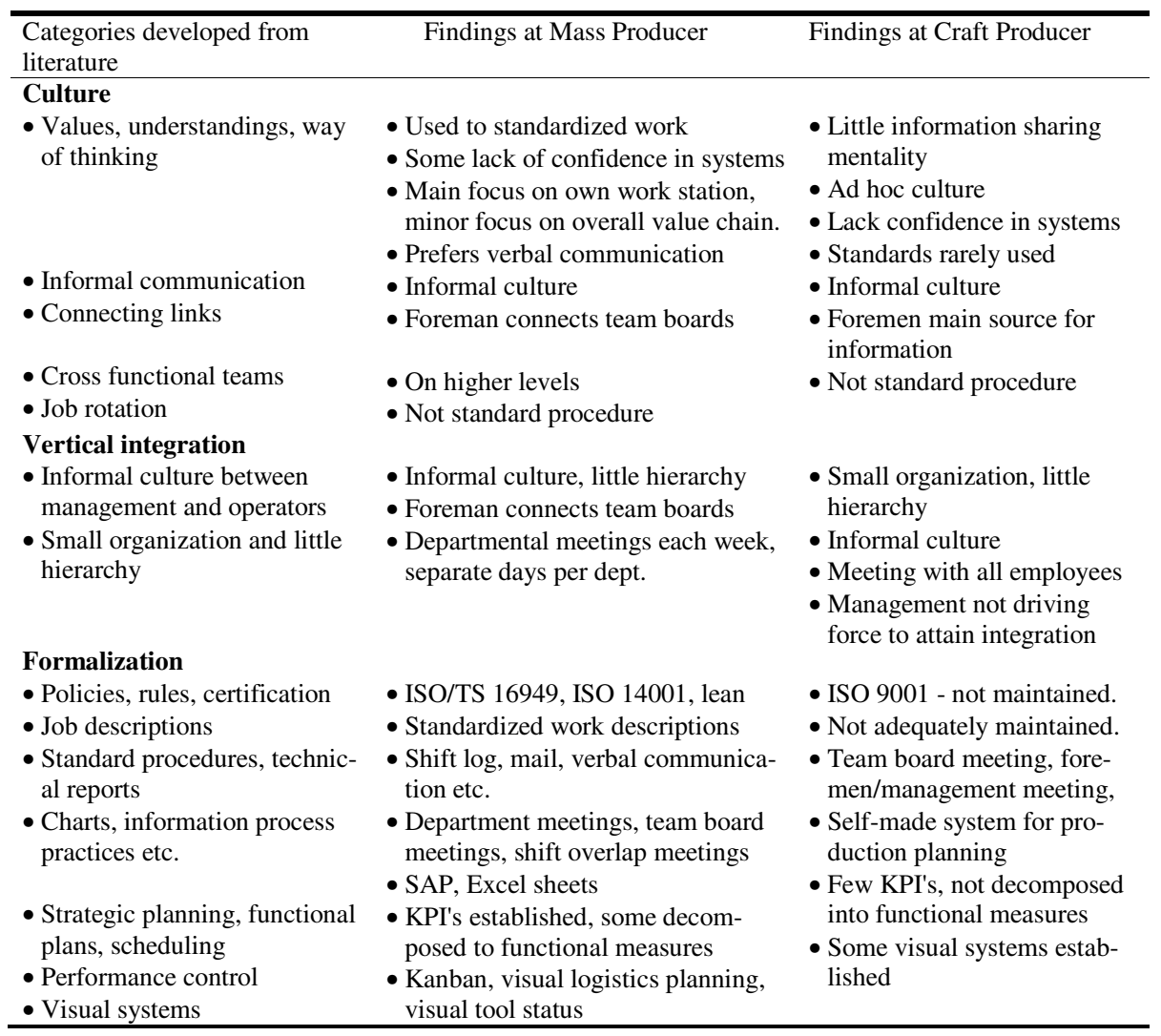


Table 3. continued. Enablers and disablers for integration in the MP and the CP

\begin{tabular}{|c|c|c|}
\hline $\begin{array}{l}\text { Categories developed from } \\
\text { literature }\end{array}$ & Findings at Mass Producer & Findings at Craft Producer \\
\hline $\begin{array}{l}\text { Facility \& Layout } \\
\text { - Plant size } \\
\text { - Physical distances } \\
\text { - Partitions }\end{array}$ & $\begin{array}{l}\text { - Large plant, small value chain } \\
\text { - Small physical distances. } \\
\text { - Intimate environment. } \\
\text { - Physical hindrances to verbal } \\
\text { - communication } \\
\text { - Functional silos }\end{array}$ & $\begin{array}{l}\text { - Small physical distances } \\
\text { - Small value chain - easier to } \\
\text { understand entire process. } \\
\text { - Intimate environment. } \\
\text { - Physical hindrances } \\
\text { - Functional silos }\end{array}$ \\
\hline \multicolumn{3}{|l|}{ Information systems } \\
\hline $\begin{array}{l}\text { - Degree of formalization of } \\
\text { information flows } \\
\text { - Enhanced capacity of infor- } \\
\text { mation processing }\end{array}$ & $\begin{array}{l}\text { - Several systems in use such as } \\
\text { ERP, document handling system, } \\
\text { mail system etc. } \\
\text { - Some lack of trust in systems }\end{array}$ & $\begin{array}{l}\text { - Few information systems in } \\
\text { use, mainly used by man- } \\
\text { agement } \\
\text { - Lack of trust in IT systems }\end{array}$ \\
\hline $\begin{array}{l}\text { Consensus integration } \\
\text { - Functional strategies must } \\
\text { support the business strategy } \\
\text { and each other. } \\
\text { - All functions support business } \\
\text { strategy and each other, and } \\
\text { all managers know this is } \\
\text { going on. }\end{array}$ & $\begin{array}{l}\text { - Operators know department strate- } \\
\text { gy, less of company strategy } \\
\text { - Some measures derived from } \\
\text { strategy, visual via team board. } \\
\text { - Operators' main focus: own work }\end{array}$ & $\begin{array}{l}\text { - Overall strategy well known, } \\
\text { but focus differs } \\
\text { - Operators' main focus: own } \\
\text { work } \\
\text { - Overall strategy not trans- } \\
\text { ferred to functional meas- } \\
\text { ures. }\end{array}$ \\
\hline $\begin{array}{l}\text { Measurement, rewards } \\
\text { - Bonuses, rewards }\end{array}$ & $\begin{array}{l}\text { - Verbal acknowledgment per num- } \\
\text { ber of improvement proposals }\end{array}$ & $\begin{array}{l}\text { - Bonus upon achieving a } \\
\text { certain number of produced } \\
\text { boats }\end{array}$ \\
\hline
\end{tabular}

\section{Culture, Social mechanisms and creation of lateral relations}

Company culture is found to affect integration. Thus, when problems arise in achieving integration, it might be helpful to try to change the culture [11].

The culture at the two plants was experienced as quite similar, despite the different structures. At both plants the operators called for more information from the management. In contrast, few of them saw the need for sharing/receiving information beyond their own process step, saying; "I have too much to do with my own work". The foremen played a superior role in information sharing, but even more at the $\mathrm{CP}$ than at the MP. This could make the foremen a bottleneck for information sharing.

Job rotation is found to contribute to achieving integration [2].At both plants there had occasionally been a rotation of workers, and this was experienced as providing more knowledge of the rest of the value chain.

\section{Vertical integration}

Both companies had an informal culture with respect to interaction between operators and management. However, the MP had more formal systems for this interaction.

The CP had one team board located in the molding department. Each morning the foreman and the operators met at the board to plan what was going to be produced. Prior to this meeting, the management and the foremen had their daily morning meeting, and the meeting in the molding area was based on output from this meeting.

The MP had one team board at each department, and the team leader participated in both these meetings. In this way the team leader acted as a connecting link between the team boards. The CP did not have the same degree of driving force for integration. 


\section{Formalization and standardization}

Standardization is one mechanism that drives integration[18], and this was found to differ between the two companies. As a result of its decades of experience with certified quality systems, the MP had several standardized procedures for information sharing. Each department used a team board and several visual systems. Despite this, there seemed to be different perceptions among some of them in terms of how information should flow.

The CP had little bureaucracy. They had earlier been ISO 9001 certified, but the systems lacked updating. A visual system for material handling was established in the previous year. The overall impression was that information sharing was more verbal than written, and that information flow was mainly single sourced, where the foremen was referred to as the person primarily responsible for information sharing.

In both companies it was experienced that the operators lacked trust in systems and found it necessary to double check information. Some called to check if emails had been received, and some verbally verified the content of operation formulas as they perceived them as insufficiently trustworthy. To achieve integration it is essential that employees comply with established and standardized systems [18].

\section{Facility \& Layout}

Both companies had small facilities, with short distances, but had separators between the process steps. The MP had a minor wall with an open connection, while the CP had a separation with a door. The presence of these partitions led to functional silos with separate cultures on each side of the partitions, and little understanding of each other's daily challenges. None of the companies had routines for job rotation, which could have contributed to increasing the understanding of the problems that occurred at the other stations and further contributed to a more holistic view of the company[2].

\section{Information systems}

The CP made little use of IT systems, and those that existed were uses primarily by the management. Some of the operators had earlier been responsible for updating the process descriptions, but in more recent years the production manager had updated them. At the MP, the operators used tools such as e-mail and registration of production data in the ERP system. But, according to one of the operators, approximately $90 \%$ of the communication was verbal. An explanation of why operators had mistrust of the IT systems at the MP could be, as claimed by one of the informants: "The IT strategy does not correspond with the overall company strategy". Use of information systems does not necessarily affect the integration positively, since how and if the information is being processed also is of importance[19).

\section{Consensus / integration}

To achieve the overall company goal, it is important to decompose the strategy into "subtasks" relevant for the employees [9]. At the CP the overall strategy was well known to all workers. However, there was little translation of this strategy into functional measures. At the MP some overall goals were decomposed into functional tasks at the production level and visualized on the team boards. Despite this, it did not seem as though the overall strategy was clear enough to all. 


\section{Measurement and rewards}

Both companies used common rewards for the departments in their value chains. The $\mathrm{CP}$ had bonuses per boat produced, while the MP used verbal acknowledgements per number of improvement proposals. These practices are in accordance with research that notes the importance of having aligned goals for the departments[10].

\subsection{Summary of Findings}

Table 3 summarizes the similarities and differences from the findings in the study.

Table 4. Summary of similarities and differences from the findings in the study

\begin{tabular}{|c|c|c|}
\hline Characteristics & Similarities & Differences \\
\hline Culture & $\begin{array}{l}\text { - Lack confidence in systems } \\
\text { - Prefer verbal communication } \\
\text { - Little information sharing mentality }\end{array}$ & $\begin{array}{l}\text { - Experience with standardized } \\
\text { work }\end{array}$ \\
\hline Vertical Integration & - Foremen main source for information & $\begin{array}{l}\text { - Foremen connecting link be- } \\
\text { tween team meetings }\end{array}$ \\
\hline Formalization & $\begin{array}{l}\text { - Informal culture } \\
\text { - Little hierarchy } \\
\text { - Little distances. }\end{array}$ & - MP more standardized than $\mathrm{CP}$ \\
\hline Facility \& Layout & $\begin{array}{l}\text { - Physical hinders } \\
\text { - Functional silos }\end{array}$ & \\
\hline $\begin{array}{l}\text { Information systems } \\
\text { Consensus integra- } \\
\text { tion }\end{array}$ & $\begin{array}{l}\text { - Lack of trust in IT systems } \\
\text { - Several operators focus mainly upon } \\
\text { their own process step }\end{array}$ & $\begin{array}{l}\text { - Different use of IT systems } \\
\text { - Company strategy well known } \\
\text { in CP less in MP } \\
\text { - Departmental strategy well }\end{array}$ \\
\hline $\begin{array}{l}\text { Measurement, re- } \\
\text { wards }\end{array}$ & $\begin{array}{l}\text { - Rewards includes more than one } \\
\text { department }\end{array}$ & known in MP minor in $\mathrm{CP}$ \\
\hline
\end{tabular}

\section{Conclusion}

The aim of this study has been to enable a better understanding of similarities and differences in mechanisms for operational integration in a craft-oriented versus a mass production enterprise. Although these companies belong to different production paradigms, they had several common enablers for integration: little hierarchy, informal culture, little distance between process steps, mutual rewards. The differences was found in degree of standardization and formalization, foremen functioning as connecting links between team boards and the fact that overall strategy is well known in $\mathrm{CP}$, while departmental strategy is more known in MP. The common disablers for integration were found to be related to culture and physical hinders in location.

The study has focused on creating new insight into enablers and disablers for operational integration in two different production paradigms and how these differ. The experiences from this study could also contribute to providing operational guidance to similar types of companies who want to improve their operational integration.

Generalization from only two single studies can of course be open to critique, but this study should contribute to building a theory of operational integration. Future research should focus on attaining more empirical results to gain knowledge of mechanisms that contributes to achieving operational integration. 


\section{References}

1. Zhou, H., Bentonjr, W.: Supply chain practice and information sharing. Journal of Operations Management 25, 1348-1365 (2007)

2. Basnet, C., Wisner, J.: Nurturing Internal Supply Chain Integration. Operations and Supply Chain Management 5, 27-41 (2012)

3. Jovane, F., Koren, Y., Boër, C.R.: Present and Future of Flexible Automation: Towards New Paradigms. CIRP Annals - Manufacturing Technology 52, 543-560 (2003)

4. Nonaka, I., Takeuchi, H.: The knowledge-creating company. Oxford University Press, New York (1995)

5. Garengo, P., Biazzo, S., Bititci, U.S.: Performance measurement systems in SMEs: A review for a research agenda. International Journal of Management Reviews 7, 25-47 (2005)

6. Shrader, C.B., Mulford, C.L., Blackburn, V.L.: Strategic and Operational Planning, Uncertainty, and Performance in Small Firms. Journal of Small Business Management 27, 45-45 (1989)

7. Koren, Y.: The global manufacturing revolution: product-process-business integration and reconfigurable systems, vol. 80. Wiley.com (2010)

8. Pagell, M.: Understanding the factors that enable and inhibit the integration of operations, purchasing and logistics. Journal of Operations Management 22, 459-487 (2004)

9. Malone, T.W., Crowston, K.: The interdisciplinary study of coordination. ACM Comput. Surv. 26, 87-119 (1994)

10. Cao, N., et al.: How are supply chains coordinated?: An empirical observation in textileapparel businesses. Journal of Fashion Marketing and Management 12, 384-397 (2008)

11. Braunscheidel, M.J., Suresh, N.C., Boisnier, A.D.: Investigating the impact of organizational culture on supply chain integration. Human Resource Management 49, 883-911 (2010)

12. Turkulainen, V.: Managing cross-functional interdependencies-the contingent value of integration. Teknillinen Korkeakoulu (2008)

13. Katz, D., Kahn, R.L.: The social psychology of organizations (1978)

14. Eisenhardt, K.M., Graebner, M.E.: Theory Building from Cases: Opportunities and Challenges. The Academy of Management Journal 50, 25-32 (2007)

15. Patton, M.Q.: Qualitative evaluation and research methods. SAGE Publications, inc. (1990)

16. Yin, R.K.: Case Study Research. Design and Methods, 4th edn., vol. 5. Sage Publications, Beverly Hills (2009)

17. Tjora, A.: Kvalitative forskningsmetoder i praksis, 2nd edn. Gyldendal Akademisk (2010)

18. Bowersox, D.J., Closs, D.J., Stank, T.P.: 21st century logistics: making supply chain integration a reality. Michigan State University, Council of Logistics Management (1999)

19. Galbraith, J.R.: Competing with flexible lateral organizations. Addison-Wesley Reading (1994) 